\title{
RESPOSTA NA PRODUÇÃO DE MUDAS DE PEPINO EM FUNÇÃO DE ADIÇÃO DE DOSAGENS DE ESTERCO DE GALINHA AO SUBSTRATO
}

\author{
Eduardo Henrique Lima Mazzuchelli ${ }^{1}$; Rita de Cássia Lima Mazzuchelli ${ }^{2}$; Pedro Veridiano Baldotto ${ }^{3}$ \\ Universidade do Oeste Paulista - UNOESTE, Programa de Pós-Graduação em Agronomia, Curso de Graduação em \\ Agronomia, Presidente Prudente - SP. E-mail: eduardomazzuchelli@yahoo.com.br
}

\section{RESUMO}

O objetivo foi avaliar a produção de mudas de pepino (Cucumis sativus L.) em função de dosagens de esterco de galinha adicionadas ao substrato. O experimento foi conduzido em estufa. Os tratamentos foram constituídos com adições crescentes de esterco de galinha curtido ao substrato, com as dosagens de $0 ; 2 ; 4 ; 8$ e $12 \%$ do substrato, totalizando cinco bandejas. As mudas foram mantidas por 15 dias em estufa. Após este período foram retiradas 40 mudas por tratamento, para as análises de número de folhas, comprimento do sistema radicular e da parte aérea da muda, massa fresca da parte aérea e do sistema radicular da muda. Para avaliar as dosagens de esterco de galinha foi aplicada a regressão polinomial e ajuste das equações. A adição de $12 \%$ do esterco de galinha ao substrato comercial para a produção de mudas de pepino foi mais eficiente, resultado em mudas com maior desenvolvimento.

Palavras-chave: Cucumis sativus L., resíduo avícola, biomassa.

\section{REPLY IN SEEDLING PRODUCTION OF CUCUMBER IN FUNCTION OF ADDED STRENGTH OF CHICKEN MANURE TO SUBSTRATE}

\begin{abstract}
The objective was to evaluate the production of seedlings of cucumber (Cucumis sativus L.) as a function of doses of chicken manure added to the substrate. The experiment was conducted in a greenhouse. Treatments were with increasing additions of manure tanned chicken to the substrate, with the levels of $0 ; 2 ; 4 ; 8$ and $12 \%$ of the substrate, totaling five trays. The seedlings were kept for 15 days in a greenhouse. After they were taken from 40 plants per treatment for analysis of number of leaves, length of root and shoot of the seedlings, fresh weight of shoot and root system of the seedling. To evaluate the dosages of chicken manure and polynomial regression fit equations were applied. The addition of $12 \%$ of chicken manure to commercial substrate for the production of cucumber seedlings was more efficient, result in seedlings with greater development.
\end{abstract}

Keywords: Cucumis sativus L., poultry manure, biomass.

\section{INTRODUÇÃO}

O pepino (Cucumis sativus L.) é uma hortaliça que pertencente a família das cucurbitáceas, assim como as abóboras. Sendo que esta cultura é uma das dez hortaliças mais cultivadas no Brasil. O seu cultivo pode ser realizado tanto a campo como em estufas, porém devem ser tutoradas. 
A qualidade das plantas no campo ou na estufa depende da forma como as mudas foram produzidas, seu subtrato, capacidade de retenção de água, balanço nutricional, isenção de patógenos e fitoparasitas.

Um recurso que cada vez mais está ganhando espaço entre as técnicas utilizadas na produção de mudas das mais diversas hortaliças é a combinação de dois ou mais substratos. Este recurso permite reaproveitar dejetos que seriam descartados da produção animal ou vegetal, incorporando esta matéria orgânica, rica em macro e micronutrientes, ao substrato comercial ou mesmo o próprio solo, havendo uma economia para o produtor rural, por se tratar de reaproveitamento de dejetos, e uma prática sustentável, já que otimiza a utilização de matéria orgânica, sem agredir o meio ambiente.

O esterco de galinha é uma ótima fonte de nutrientes, possui uma alta concentração de nutrientes mesmo em pequenas porções de esterco, se comparado a outros tipos, como o de gado, por exemplo, enriquecendo assim a mistura com o substrato comercial e sendo uma pratica economicamente viável ao produtor de mudas, já que reaproveita o dejeto da produção de aves, e disponibiliza diversos macro e micronutrientes ao substrato utilizado na produção das mudas, o que diretamente interferirá no vigor e qualidade da muda, sendo um fator exponencial a planta adulta no campo ou estufa.

No caso a utilização do substrato enriquecido com o esterco de galinha, ainda adquire outras características de um bom substrato para mudas de hortaliças, como a capacidade de retenção e absorção de água, devido aos coloides da matéria orgânica, condições de aeração as raízes, capacidade de disponibilização imediata de macro e micronutrientes, isenção de patógenos e organismos saprófitas além de ser considerado leve.

O objetivo do presente trabalho foi o de avaliar a produção de mudas de pepino (Cucumis sativus L.) em função de dosagens de esterco de galinha adicionadas ao substrato.

\section{METODOLOGIA}

O experimento foi conduzido em casa de vegetação localizada no Campus II da Universidade do Oeste Paulista (UNOESTE) - Faculdade de Ciências Agrárias, em Presidente Prudente - SP, nos meses de março a abril de 2014. As coordenadas do local são latitude de $22^{\circ} 07^{\prime} 04^{\prime \prime}$ e longitude de $51^{\circ} 22^{\prime} 04^{\prime \prime}$ e altitude de aproximadamente 432 metros acima do nível do mar. 
O clima da região é pela classificação de Köppen Aw como mesotérmico com verões quentes e período chuvoso bem definido nos meses de setembro a março e invernos secos com temperaturas mais amenas nos meses de abril a setembro.

Para o desenvolvimento do experimento foi utilizado o substrato comercial Bioplant ${ }^{\circledR}$, para o preenchimento de cinco bandejas de poliestireno expandido com 200 células.

Os tratamentos foram constituídos com adições crescentes de esterco de galinha curtido ao substrato, com as dosagens de 0; 2; 4; 8 e 12\% do substrato comercial, correspondentes a 0; 0,$5 ; 1,0 ; 2,0 ; 3,0$ kg em 25 kg do substrato Bioplant ${ }^{\circledR}$.

Os tratamentos foram utilizados para preencher alternadamente as fileiras da bandeja, em cada célula foi adicionada uma semente de pepino, cultivar Green Pick, da empresa Isla ${ }^{\circledR}$.

As mudas foram mantidas por 15 dias em estufa, recebendo irrigação periódica. Após este período foram retiradas oito mudas aleatoriamente de cada bandeja, totalizando quarenta mudas de cada tratamento para as análises:

a) Número de folhas por muda, considerando-se todas as folhas que apresentam tamanho mínimo superior a $1,0 \mathrm{~cm}$;

b) Massa fresca da parte aérea da muda, aferido após o corte rente ao substrato;

c) Massa fresca do sistema radicular da muda, após a remoção do substrato aderido as raízes;

d) Comprimento da parte aérea da muda, com auxílio de régua;

e) Comprimento do sistema radicular da muda, com auxílio de régua;

Os dados obtidos foram submetidos à análise de variância ANOVA através do programa Sisvar (FERREIRA, 2008). Para avaliar as doses de esterco de galinha será aplicada a regressão polinomial e ajuste das equações.

\section{RESULTADOS}

A análise do número de folhas mostrou um comportamento linear crescente em resposta às dosagens de esterco de galinha aplicadas ao substrato. Portanto, o tratamento com a aplicação de $12 \%$ do esterco proporcionou um maior desenvolvimento de folhas, consequentemente, estas poderão produzir mais fotoassimilados em relação aos demais tratamentos, por atingirem maior taxa de fotossíntese líquida (Figura 1). 


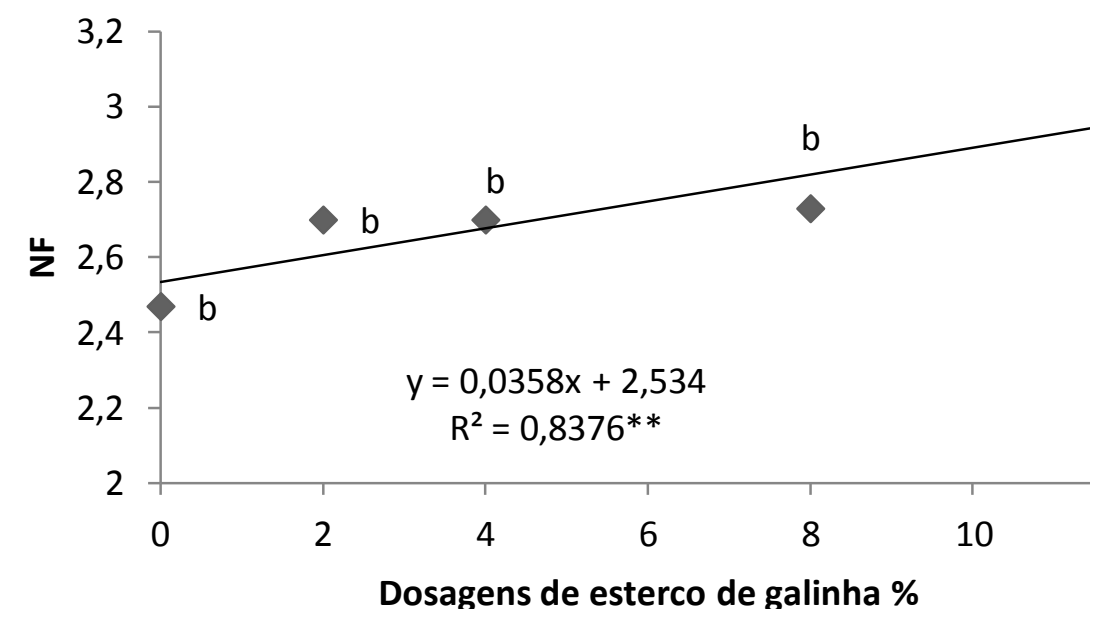

Figura 01. Número de folhas (NF planta ${ }^{-1}$ ) das mudas de pepino submetidas a dosagens crescentes de esterco de galinha ao substrato.

$\mathrm{Na}$ avaliação do comprimento da parte aérea - CPA, das mudas de pepino, podemos observar um linear crescente em resposta às dosagens de esterco de galinha adicionadas ao substrato. O tratamento com a aplicação de $12 \%$ do esterco resultou um maior crescimento das mudas, quando comparadas aos demais tratamentos efetuados (Figura 2).

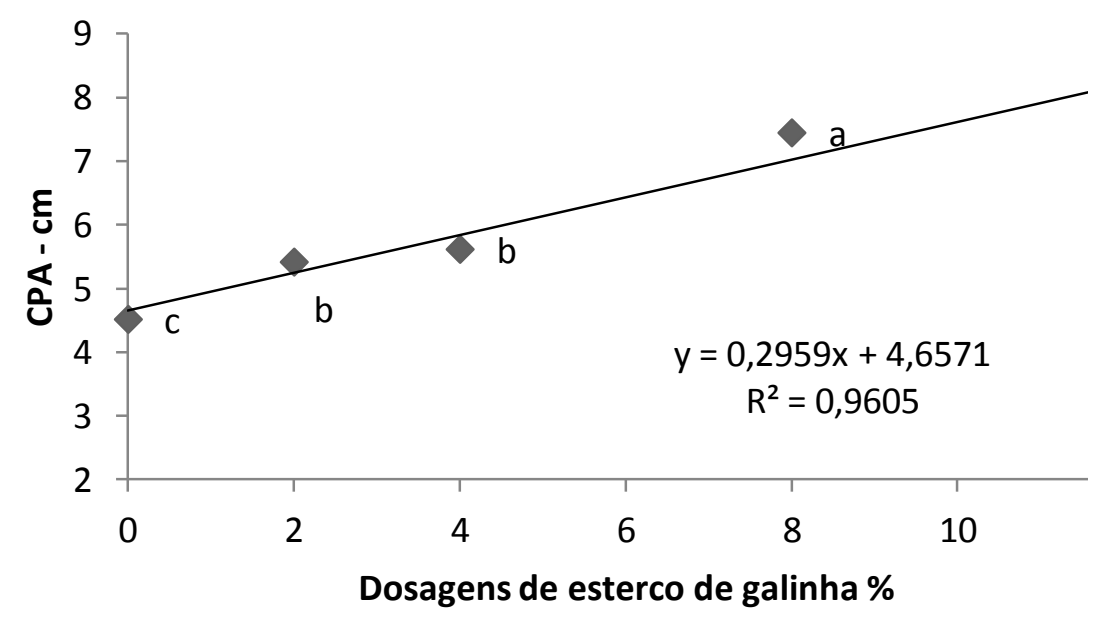

Figura 02. Comprimento da parte aérea $\left(C P A-\mathrm{cm}_{\text {planta }}{ }^{-1}\right)$ das mudas de pepino submetidas a dosagens crescentes de esterco de galinha ao substrato.

A análise do crescimento do sistema radicular - CSR, apresentou um comportamento linear crescente em resposta às dosagens de esterco de galinha aplicadas ao substrato para a confecção das mudas. O tratamento com a aplicação de $12 \%$ do esterco ao substrato proporcionou um maior crescimento das raízes, em relação aos outros tratamentos efetuados (Figura 3). 


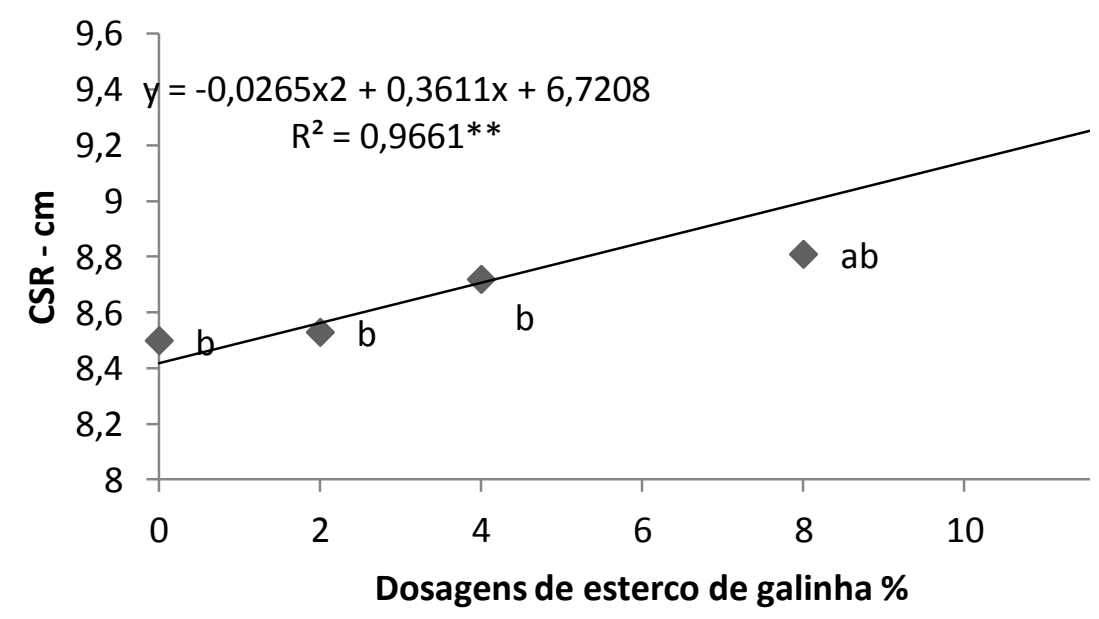

Figura 03. Comprimento do sistema radicular (CSR $\left.-\mathrm{cm}_{\text {planta }}{ }^{-1}\right)$ das mudas de pepino submetidas a dosagens crescentes de esterco de galinha ao substrato.

A análise da massa fresca da parte aérea - MFPA, das mudas de pepino mostrou um comportamento linear crescente em resposta às dosagens de esterco de galinha adicionadas ao substrato.

O tratamento com a adição de $12 \%$ do esterco proporcionou um maior desenvolvimento da parte aérea das mudas, comparadas aos demais tratamentos efetuados, com o comportamento linear crescente (Figura 4).

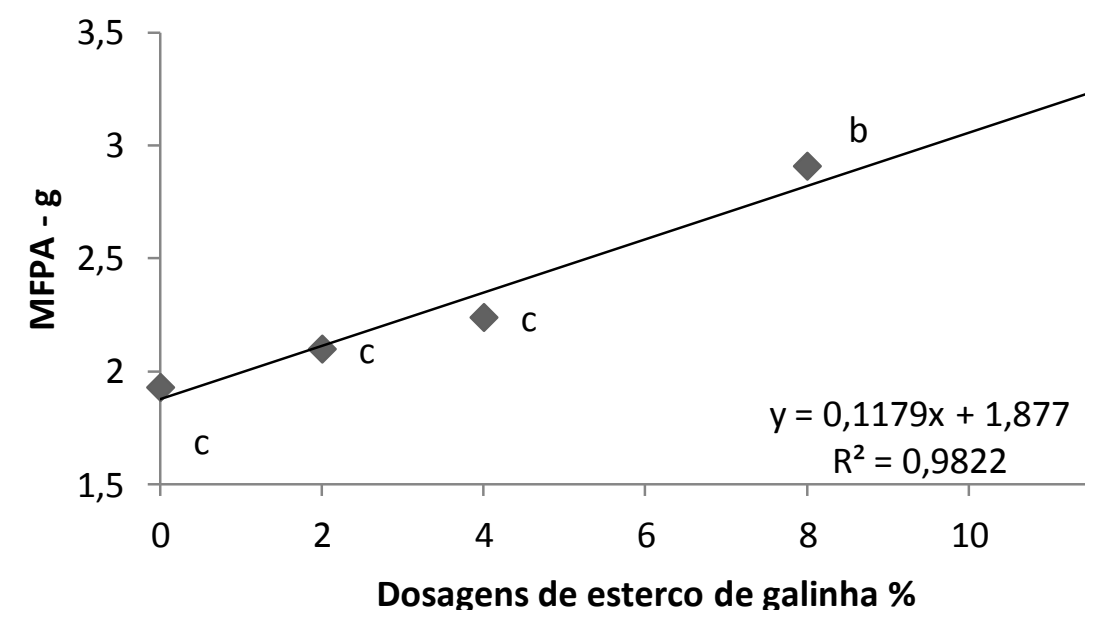

Figura 04. Massa fresca da parte aérea (MFPA - gramas planta ${ }^{-1}$ ) das mudas de pepino submetidas a dosagens crescentes de esterco de galinha ao substrato. 
$\mathrm{Na}$ avaliação da massa fresca do sistema radicular - MFSR, as mudas de pepino apresentaram um comportamento linear crescente em resposta às dosagens de esterco de galinha aplicadas ao substrato (Figura 5).

O tratamento com a aplicação de $12 \%$ do esterco proporcionou um maior desenvolvimento das raízes, consequentemente, estas, além de possuírem um maior crescimento (Figura 3) poderão explorar níveis mais profundos do solo quando forem transplantadas, por apresentaram maior desenvolvimento das raízes.

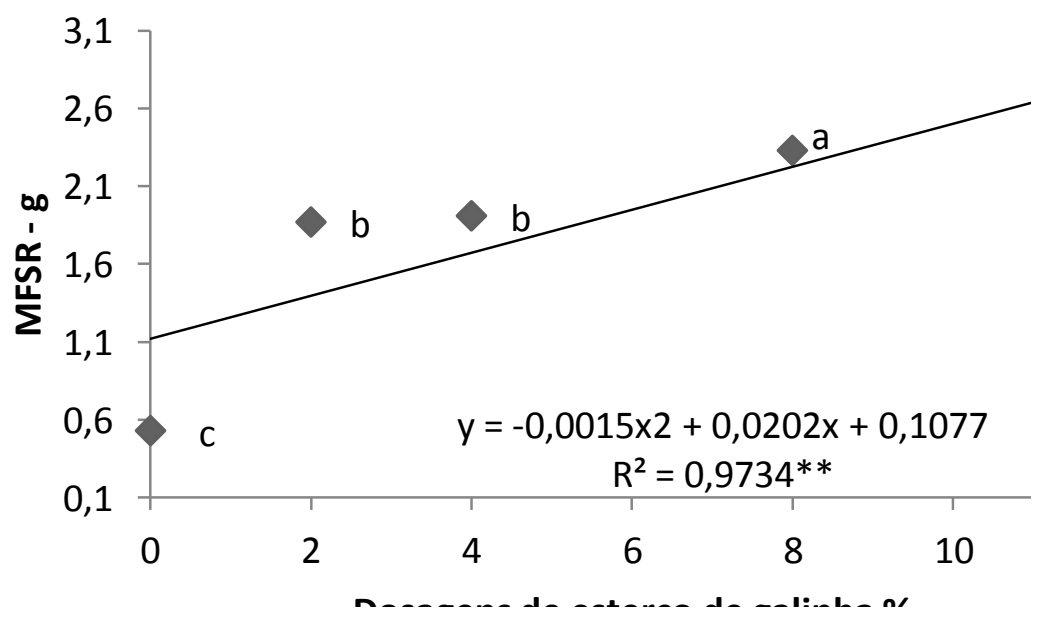

Figura 05. Massa fresca do sistema radicular (MFSR - gramas planta ${ }^{-1}$ ) das mudas de pepino submetidas a dosagens crescentes de esterco de galinha ao substrato.

\section{DISCUSSÃO}

Caldeira et al. (2012) contataram que a utilização de substratos formulados com resíduos sólidos do abate de frango, com resíduos da indústria de arroz se mostraram mais eficientes no crescimento de plantas de pepino, quando comparados ao substrato isolado.

A área foliar e, consequentemente, o índice de área foliar são de suma importância para que se possa modelar o crescimento e o desenvolvimento das plantas e, por conseguinte, a produtividade total da cultura. A área foliar de uma planta depende do número e do tamanho das folhas e do seu tempo de permanência na planta, isto é, pode variar ao longo do ciclo da cultura. As culturas devem ter sua semeadura programada de modo que os valores máximos do índice de área foliar coincidam com a época de elevada radiação, quando então a fotossíntese líquida será máxima (REIS et al., 2013).

Soares et al. (2008) testando diferentes substratos para a produção de mudas de pepino, observaram que todos os substratos testados viabilizaram a produção de mudas de pepino, 
porém, ressalta que a textura dos mesmos é um fator de extrema importância na manutenção de umidade do substrato, uma vez que maiores umidades permitem um estabelecimento mais rápido de mudas e também a produção de mudas mais vigorosas.

Costa et al. (2010) garante que há a necessidade de se verificar experimentalmente, para cada espécie vegetal, o melhor tipo de substrato ou a melhor mistura de substratos que permita a obtenção de plantas vigorosas. Sendo que a utilização de resíduos na formulação de substratos, além de contribuir para a redução do impacto dos mesmos ao meio ambiente, também proporciona redução de custos, quando disponíveis na região de produção.

\section{CONCLUSÃO}

A adição da dosagem de $12 \%$ do esterco de galinha ao substrato comercial para a produção de mudas de pepino foi mais eficiente, resultado em mudas com maior desenvolvimento. Possivelmente dosagens maiores poderiam contribuir para um maior desenvolvimento de mudas de pepino, necessitando de outros estudos para tal afirmação.

\section{REFERÊNCIAS}

CALDEIRA, M.V.W.; HARBS, R.M.P.; TAVARES, L.B.B.; SPERANDIO, H.V.; SANTOS, F.E.V. Avaliação do composto orgânico de resíduos de abatedouro de frangos na produção de mudas. Revista Verde de Agroecologia e Desenvolvimento Sustentável, v.7, n.2, p 212-215, 2012.

COSTA, E.; LEAL, P. A. M.; GOMES, V. A.; MACHADO, D.; JARA, M. Biomassa de mudas de pepinos híbridos conduzidos sob ambientes protegidos. Bragantia, v. 69, n. 2, p. 381-386, 2010.

http://dx.doi.org/10.1590/S0006-87052010000200017

FERREIRA, D.F. SISVAR: um programa para análises e ensino de estatística. Revista Symposium, v.6, p.36-41, 2008.

REIS, L.S.; AZEVEDO, C.A.V.; ALBUQUERQUE, A.W.; SOUZA JÚNIOR, J.F; Índice de área foliar e produtividade do tomate sob condições de ambiente protegido. Revista Brasileira de Engenharia Agrícola e Ambiental, v.17, n. 4, p386-391, 2013. http://dx.doi.org/10.1590/S1415$\underline{43662013000400005}$

SOARES, E. R.; RUI, T. L.; BRAZ, R. F.; KANASHIRO JUNIOR, W. K. Desenvolvimento de mudas de pepino em substratos produzidos com resíduos de algodão e de poda de árvores. VI Encontro Nacional sobre substratos para plantas materiais regionais como substrato. Fortaleza - CE. 2008. 